\title{
DIRETRIZES DE INFRAESTRUTURA VERDE PARA O DESENHO URBANO: UM EXERCíCIO DE PLANEJAMENTO PAISAGÍSTICO NA ÁREA DA LUZ, SÃO PAULO.
}

\author{
LUCIANA SCHWANDNER FERREIRA* \\ *Mestre pela Faculdade de Arquitetura e Urbanismo, Universidade de São Paulo \\ e-mail: luciana.swf@gmail.com \\ Patrícia Mara Sanches** \\ **Mestre em Paisagem e Ambiente, Faculdade de Arquitetura e Urbanismo, Universidade de São Paulo \\ e-mail: patricia.msanches@uol.com.br \\ Paula Shinzato ${ }^{* * *}$ \\ ***Doutoranda pela Faculdade de Arquitetura e Urbanismo, Universidade de São Paulo \\ e-mail: paulashinzato@yahoo.com \\ Joana Carla S. Goncalves**** \\ ${ }^{* * * *}$ Prof. Dra. da Faculdade de Arquitetura e Urbanismo, Universidade de São Paulo do Departamento de Tec- \\ nologia da Arquitetura e do Urbanismo, Laboratório de Conforto Ambiental e Eficiência Energética, LABAUT. \\ Professora Orientadora do Programa de Pos Graduação, Environment and Energy, da Architectural Asso- \\ ciation Graduate School, AA School of Architecture, Londres. \\ e-mail: jocarch@usp.br
}

\section{RESUMO}

A presente pesquisa apresenta diretrizes projetuais para o planejamento e projeto de novas áreas verdes públicas e semi-públicas, cujas funções e distribuição foram definidas a partir dos conceitos de infraestrutura verde e aplicadas na Área da Luz, na cidade de São Paulo. Esta pesquisa está inserida em um projeto interdisciplinar desenvolvido pelo Laboratório de Conforto Ambiental e Eficiência Energética (Labaut) da Faculdade de Arquitetura e Urbanismo, Universidade de São Paulo que propõe uma intervenção no ambiente construído visando o adensamento populacional e construtivo sob a perspectiva do desempenho ambiental. O método de trabalho consistiu primeiramente na caracterização das seguintes questões: áreas verdes existentes dentro da área de estudo e do entorno; fluxo de pedestres e ciclistas e dinâmica de insolação da área. $O$ cruzamento dos resultados permitiu direcionar a vocação das áreas verdes e definir objetivos, diretrizes e estratégias. Os quatro principais objetivos definidos foram ampliar a oferta de espaços livres, proporcionar qualidade ambiental para o pedestre, melhorar drenagem e aumentar a biodiversidade local. Como resultado verificou-se um aumento de $1.200 \%$ na quantidade de espaços livres vegetados 
da área de estudo, passando de $5.033 \mathrm{~m}^{2}$ para $60.450 \mathrm{~m}^{2}$. A pesquisa insere conceitos ainda pouco utilizados na prática comum de projetos paisagístico na escala urbana em cidades brasileiras, partindo-se da premissa que as áreas verdes fazem parte de um sistema infra-estrutural e que desempenham diversas funções na cidade.

Palavras-chave: Infraestrutura Verde; Vegetação Urbana; Floresta Urbana; Planejamento Ambiental; Revitalização Urbana.

\title{
GUIDELINES OF GREEN INFRASTRUCTURE FOR URBAN DESIGN: AN EXER- CISE OF LANDSCAPE PLANNING AT LUZ DISTRICT, SÃO PAULO
}

\begin{abstract}
This research presents projective guidelines for the planning and design of new public and semi-public green areas, which functions and distribution were defined based on the concepts of green infrastructure and applied at the area of Luz District, in São Paulo. This research is part of a multidisciplinary project developed by Laboratory of Environmental Comfort and Energy Efficiency (LABAUT), of the Faculty of Architecture and Urbanism, University of São Paulo, and propose an intervention in the built environment aiming the population and constructive densification under the perspective of environmental performance. The working method consisted primarily in the characterization of the following issues: existing green areas within the analyzed area and surroundings; flow of pedestrians; and, cyclists and insolation dynamic of that area. The intersection of results allowed conducting the vocation of green areas and setting targets, guidelines and strategies. The four main objectives were defined to increase the offer of open spaces, provide an environmental quality for pedestrians, improve drainage and increase local biodiversity. As a result there was an increase of $1,200 \%$ in the amount of green open spaces in the focused area, rising from 5.033sqm to 60.450sqm. The research includes concepts still little used in common practice of landscape projects in urban scale at Brazilian cities, starting from the premise that the green areas take part of a infrastructural system that perform various functions in the city.
\end{abstract}

Keywords: Green Infrastructure; Urban Vegetation; Urban Forest; Environmental Planning; Urban Revitalization. 


\section{INTRODUÇÃO}

A ausência de áreas vegetadas é um problema comum na maioria dos aglomerados urbanos brasileiros principalmente aqueles que foram submetidos a uma urbanização rápida e sem um planejamento preocupado com as questões ambientais. (Sanches, 2011). A supressão das áreas verdes afeta não apenas a qualidade de vida da população pela falta de opções de lazer e recreação, mas também potencializa a ocorrência de inundações, a concentração de poluentes no ar, a alteração do microclima urbano e a formação das ilhas de calor ${ }^{1}$, além de interferir, do ponto de vista ecológico, na diminuição da biodiversidade urbana e peri-urbana.

Há ampla literatura e pesquisas que evidenciam que a população urbana precisa de contato com a natureza. Alguns chegam a ser matemáticos em suas argumentações, como Johnston ${ }^{2}$ (apud HERBST,2001) que menciona que áreas verdes devem estar a uma distância entre 5 e 10 minutos a pé das residências. Chaddad (2000) vê uma clara correlação entre quantidade de áreas vegetadas de uma cidade e a qualidade de vida que esta oferece aos seus habitantes, como a promoção do bem estar, de práticas esportivas, maior socialização e estímulo à identidade da comunidade com o local, exercendo assim um "papel de agente catalisador e motivador de congregação comunitária" (CHADDAD, 2000). Atualmente dados relacionados à quantidade e à distribuição das áreas verdes fazem parte da relação de indicadores e parâmetros de avaliação da qualidade de vida das cidades.

Apesar do progressivo reconhecimento dos benefícios dos espaços vegetados pelas autoridades públicas, a manutenção ou criação de novas áreas verdes em cidades com alta densidade construída - na qual a terra é um recurso escasso e caro - é um grande entrave, tanto do ponto de vista físico, como econômico. Porém, o maior desafio é vislumbrar novas áreas verdes sem deixar de pensar no papel multifuncional que elas podem oferecer à cidade, atentando às suas potencialidades e seus benefícios de maneira holística, aproveitando as inúmeras funções dos espaços vegetados, entendidos, dessa forma, como sistemas que compõe uma infraestrutura verde.

\footnotetext{
${ }^{1} \mathrm{O}$ fenômeno climático conhecido como ilha de calor caracteriza-se pela maior temperatura noturna em áreas densamente construídas em comparação com seu entorno rural. Algumas características das estruturas urbanas, como a relação entre a largura das ruas e a altura dos edifícios, os tipos de materiais construtivos utilizados e a quantidade e localização das áreas verdes afetam a intensidade da ilha de calor (GIVONI, 1998; LOMBARDO, 1985).

2 JOHNSTON, J. Nature areas for city people. Ecology Handbook n.14 London Ecology Unit. 1990.
} 
Assim, não se trata de um sistema convencional de espaços livres e áreas verdes. A concepção dos espaços vegetados como parte da infraestrutura verde urbana é uma estratégia de estruturação dos espaços naturais e ambientalmente recuperados no processo de planejamento e desenho da cidade e já vem sendo aplicada em muitas cidades, principalmente na Europa e nos Estados Unidos.

A terminologia infraestrutura atrelada à palavra "verde" deve-se à sua contribuição nas funções de base estrutural da cidade, como por exemplo, o sistema viário, de energia ou de abastecimento de água (PELLEGRINO, 2006), que contribuem para o bom funcionamento da cidade e atendem aos padrões mínimos de habitabilidade, qualidade de vida, saneamento básico e saúde pública. Dessa mesma forma, a infraestrutura verde pode atuar conjuntamente com outros sistemas, no atendimento:

- da mobilidade e acessibilidade, ao direcionar e estruturar eixos de circulação, e ao propiciar rotas específicas ou alternativas para pedestres e ciclistas;

- da drenagem das águas pluviais, regulando o ciclo hídrico, atenuando os picos de cheia e conduzindo as águas com segurança;

- do lazer, da recreação e do convívio social, além de serem espaços de contemplação e percepção estética;

- da manutenção dos processos ecológicos, da biodiversidade e da sustentabilidade dos ecossistemas, colaborando com o aumento da conectividade dos fragmentos naturais.

Cormier (2008) complementa este quadro de funções citando o sistema metabólico da cidade, que está relacionado aos fluxos intra-urbanos de energia e matéria. A agricultura urbana, neste caso, é mencionada como um exemplo deste sistema metabólico, se utilizando das áreas verdes para um propósito produtivo, de atendimento das necessidades básicas de saúde do ser humano. Complementarmente, a infraestrutura verde também tem um papel fundamental para a criação de condições de conforto térmico nos espaços abertos. O efeito da sombra criada pela vegetação, por exemplo, proporciona maior conforto aos espaços de lazer e recreação e maior qualidade no percurso de pedestres e ciclistas.

Os elementos que compõe a infraestrutura verde são os espaços abertos e vegetados, como parques, praças, corredores ecológicos, remanescentes florestais, 
alagados naturais e construídos, jardins, tetos verdes, etc., aliados em alguns casos a tecnologias ambientais, como tratamento com fitorremediação, materiais e pavimentos filtrantes, sistemas de irrigação mais eficiente, placas fotovoltaicas promovendo melhoria na qualidade ambiental e ganhos sociais e econômicos.

Além da ausência de uma visão multifuncional das áreas verdes urbanas, outra dificuldade para sua implementação pelas atuais administrações municipais brasileiras é a falta de metodologias, critérios e diretrizes para compor programas e políticas públicas. A este cenário, soma-se a inexistência ou as fracas articulações e parcerias entre os diferentes órgãos públicos responsáveis pela gestão da cidade, assim como, entre o poder público e as instituições de pesquisa, ONG's, sociedade civil e iniciativa privadas, desperdiçando oportunidades valiosas de se colocarem em prática novas teorias urbanísticas e paisagísticas, de trocar experiências e obter maior participação e envolvimento da comunidade nas decisões políticas e rumos das cidades.

Neste contexto, a presente pesquisa propõe diretrizes de projeto para a implantação de novas áreas verdes na área da Luz, no bairro de Santa Efigenia, centro da cidade de São Paulo. A partir do estabelecimento de quatro objetivos principais a serem alcançados com a intervenção foram definidas diretrizes de projeto que seguem as premissas da infraestrutura verde.

As funções das novas áreas verdes e sua distribuição espacial foram definidas a partir dos conceitos de infraestrutura verde e aplicadas aos novos espaços livres resultantes de uma proposta de adensamento urbano com qualidade ambiental com foco na área da Luz, no bairro de Santa Efigenia, em São Paulo, da qual esta pesquisa fez parte. - . Esta proposta insere-se em um projeto de pesquisa piloto desenvolvido pelo Laboratório de Conforto Ambiental e Eficiência Energética (Labaut) da Faculdade de Arquitetura e Urbanismo, Universidade de São Paulo e apresentado na conferência internacional Urban Age-São Paulo 2008³ , ocorrida em dezembro do mesmo ano, na cidade de São Paulo, com o apoio da Prefeitura e de uma serie de instituições de pesquisa.

Este grande projeto interdisciplinar consistiu em uma proposta de intervenção no ambiente construído visando o adensamento populacional e construtivo sob a perspectiva do desempenho ambiental. Por meio da requalificação do espaço urbano, do

\footnotetext{
${ }^{3}$ Urban Age: http://lsecities.net/ua/conferences/2008-sao-paulo/
} 
uso eficiente da infraestrutura, da reabilitação tecnológica de edifícios existentes e da inserção de novos edifícios, propõe-se atingir a meta de 2.500 pessoas/hectare (GONCALVES et al, 2011).

\section{ESTUDO DE CASO: A ÁREA DA LUZ, SÃO PAULO.}

De acordo com os dados do Atlas Ambiental de São Paulo (SMVA, 2000), 48\% do território do município de São Paulo são carentes em arborização e áreas verdes. As áreas mais deficitárias, segundo SVMA ${ }^{4}$, situam-se nas Administrações Regionais de Aricanduva/Vila Formosa, Itaim Paulista e Vila Prudente (Zona Leste); Cidade Ademar e Jabaquara (Zona Sul); Casa Verde, Vila Maria/Vila Guilherme (Zona Norte); e Sé e Mooca (Zona Central).

É importante destacar que os distritos que compõem a Zona Central de São Paulo apresentam as menores quantidades de cobertura vegetal por habitante, na Sé, distrito onde se localiza a área da Luz, tem-se $0,21 \mathrm{~m}^{2} / \mathrm{hab}$, na República $0,24 \mathrm{~m}^{2} /$ hab, na Bela Vista $0,11 \mathrm{~m}^{2} / \mathrm{hab}$, sendo que no distrito de Santa Cecília e do Brás tal índice é de $0 \mathrm{~m}^{2} / \mathrm{hab}$.

A redução das áreas verdes em São Paulo é causada não apenas pelas ocupações ilegais e assentamentos irregulares, mas também pelo crescente processo de impermeabilização do solo por meio da construção de edifícios e novas vias públicas.

A alta densidade construída na área da Luz contrasta com a baixa densidade demográfica. Apesar da elevada taxa de ocupação do solo (aproximadamente $80 \%$ ) e do aglomerado de edifícios que podem ser considerados altos no contexto local (alguns com mais de vinte pavimentos), atualmente, a densidade média do Distrito da Sé ao qual pertence a área de estudo - é de $11.262 \mathrm{hab} / \mathrm{km}^{2}$, valor baixo se comparado com cidades como Paris, com 20.980 hab $/ \mathrm{km}^{2}$ ou Barcelona, com $17.451 \mathrm{hab} / \mathrm{km}^{2}$, que conseguem aliar alta densidade com elevada qualidade de vida.

O potencial de adensamento habitacional da região pela farta infraestrutura de transporte e edifícios existentes serviu de base para as primeiras iniciativas do poder

\footnotetext{
${ }^{4}$ Disponível em: <http://atlasambiental.prefeitura.sp.gov.br/conteudo/socioambiental/socioamb_05_tab.htm >. Acesso em agosto de 2011.
} 
público de revitalização dessas áreas, iniciadas na década de 1990. Vale destacar que a área de estudo vem vivenciando nas últimas três décadas diversos problemas sociais relacionados à segurança, como o aumento da criminalidade, vandalismo e tráfico de drogas (resultando na região conhecida como "Cracolândia"), intensificando a degradação física e desvalorização econômica da área central.

Nesse contexto de iniciativas de transformação urbana, em 2005 foram anunciados os planos para o projeto intitulado Nova Luz, considerado um projeto de requalificação urbana empreendido pela Prefeitura de São Paulo, abrangendo aproximadamente uma área de 225 hectares. Este projeto, lançado no domínio público na forma de uma concorrência de técnica e preço em 2010, prevê a valorização dos prédios históricos, reforma das áreas livres públicas, criação de espaços verdes e de lazer, e a melhoria do ambiente urbano da região, dentre outras ações socioeconômicas.

Para viabilizar a realização do projeto Nova Luz, foram aprovadas legislações específicas, estabelecendo incentivos fiscais para a instalação de empresas de tecnologia e outros serviços na região e declarando de utilidade pública algumas áreas passíveis de desapropriação.

Como forma de participar dessa discussão e estimular a reflexão e pensamento critico e investigativo, a área da Luz foi escolhida como estudo de caso dessa pesquisa, que discute a requalificação dos espaços livres e áreas verdes por meio de uma abordagem ambiental de inserção desses espaços na estrutura produtiva da cidade, incorporando ao seu conhecido papel recreacional, novos papéis, como o microclimático e o da biodiversidade.

\section{O PROJETO DE REVITALIZAÇÃO NA ÁREA DA LUZ}

O projeto piloto desenvolvido pelo Laboratório de Conforto Ambiental e Eficiência Energética (Labaut) da FAUUSP focou no desempenho ambiental da forma urbana, com especial atenção para as condições ambientais criadas nos espaços abertos, para o qual a infraestrutura verde teve um papel central. Tal projeto partiu do pressuposto de que a forma urbana afeta o futuro das cidades e a sua sustentabilidade, e que os centros urbanos ainda podem acomodar milhões de pessoas com qualidade e dignidade. Assim, o objetivo foi propor, por meio de uma abordagem multidisciplinar, uma metodologia para projetos urbanos que considerasse ao mesmo tempo o aden- 
samento construído e populacional, e a promoção da qualidade ambiental e demais benefícios sócio-econômicos.

Como objetivos específicos, buscou-se:

- o uso eficiente das infraestruturas urbanas existentes, com ênfase para a questão da mobilidade urbana;

- redução da demanda de energia elétrica dos edifícios (por meio da captação da energia solar na estrutura dos próprios edifícios);

- o conforto ambiental nas edificações e espaços livres;

- a dispersão de poluentes facilitada pela eficiente ventilação urbana,

- a criação de novas áreas verdes desempenhando funções sociais, ambientais e econômicas.

A área de intervenção abrange 25 quadras, totalizando aproximadamente 27 hectares, dentro do perímetro definido pelas Avenidas Ipiranga, Rio Branco, Duque de Caxias, Rua Mauá e Avenida Cásper Líbero, na área da Luz, região central de São Paulo.

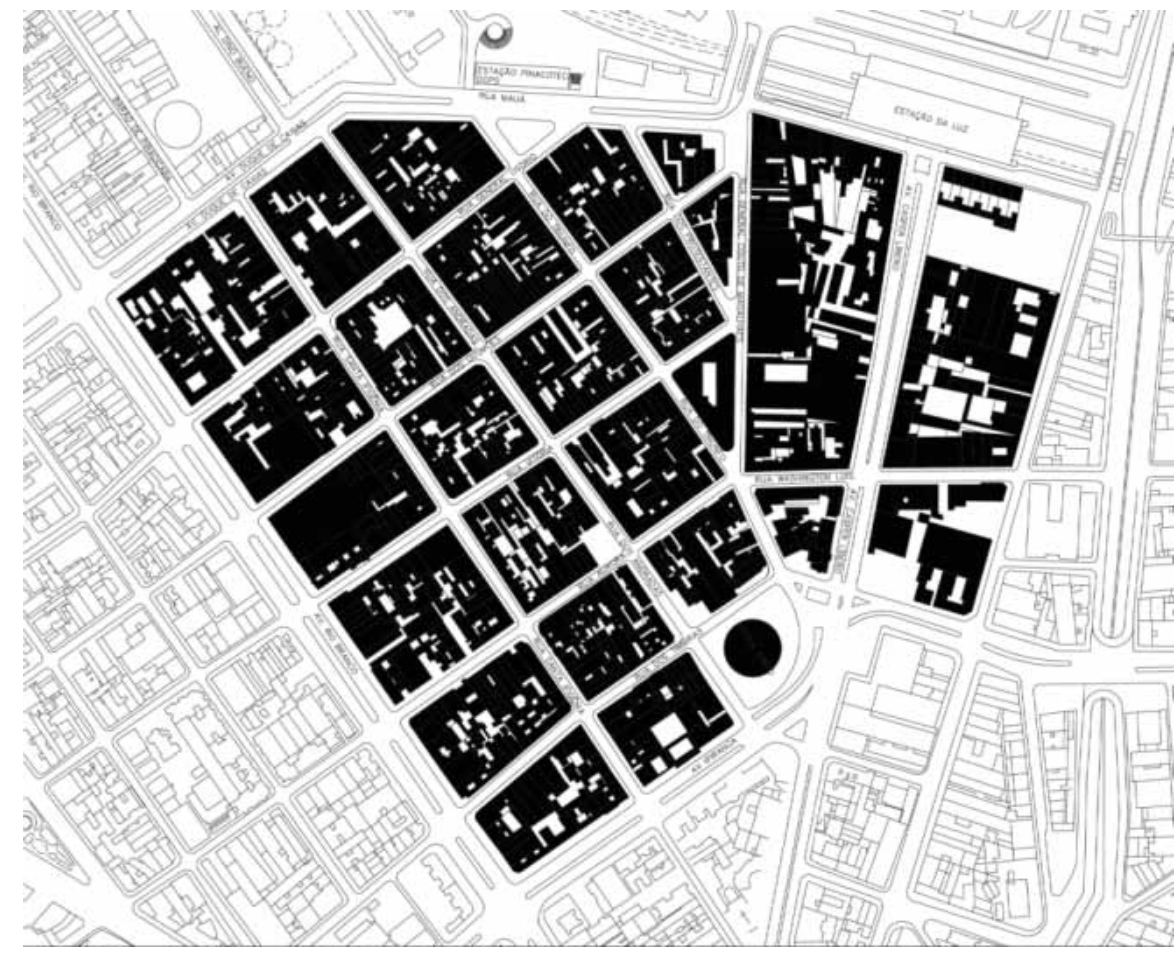

Figura 1 - Conjunto edificado atualmente existente na área de estudo, Bairro da Luz, São Paulo 
A primeira etapa do projeto constituiu em uma proposta de demolição de um conjunto de edifícios desocupados, degradados fisicamente e com menos de cinco andares, para que fosse possível o aumento da densidade construída. O resultado apresentase nas imagens abaixo, a figura 1 mostra a situação atual de ocupação dos edifícios, enquanto a figura 2 apresenta a área após a supressão de alguns edifícios, de acordo com os critérios mencionados acima.

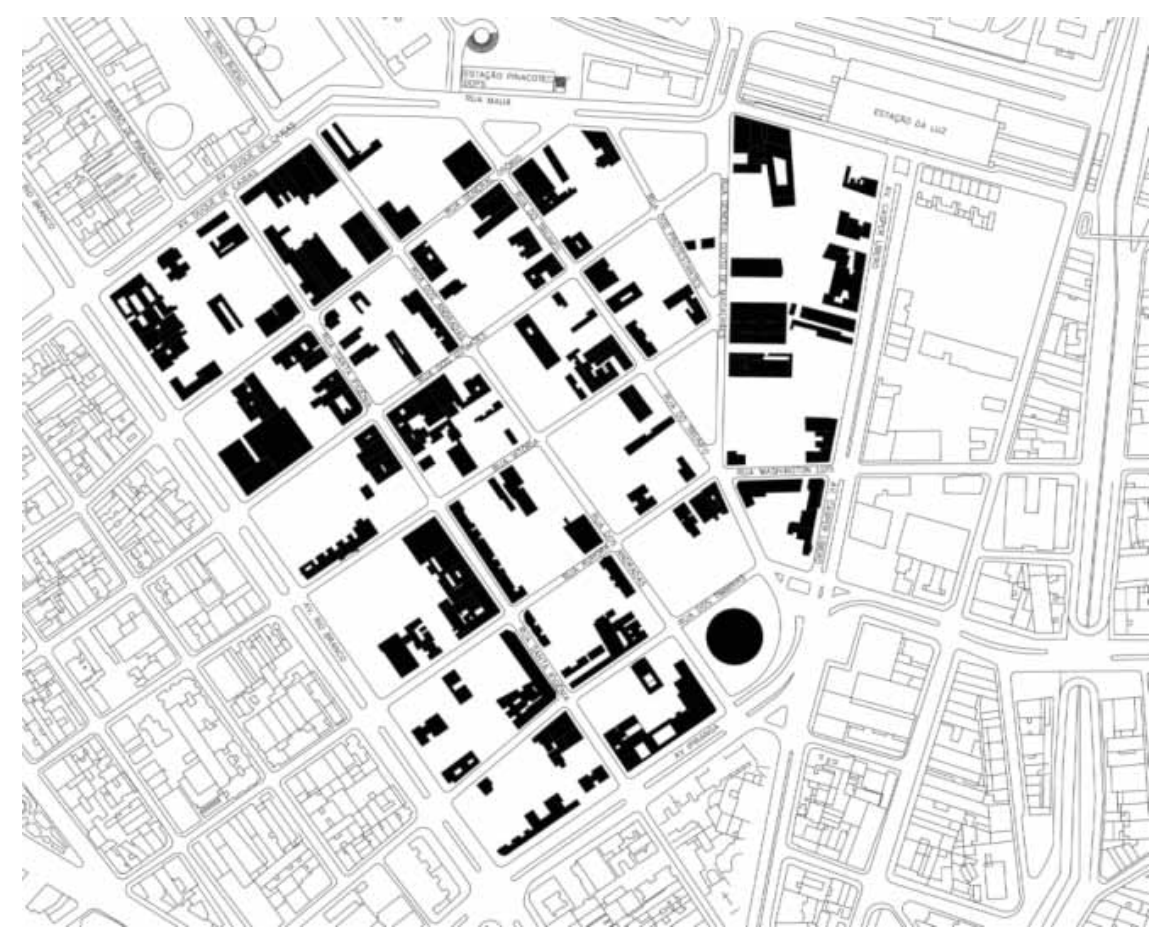

Figura 2 - Mapa com a proposta de supressão da edificação existente, resultando em novos espaços livres a serem ocupados por novos edifícios e áreas verdes.

Baseadas numa densidade pré-determinada de 25.000 hab $/ \mathrm{Km}^{2}$, foram elaboradas duas propostas de desenho urbano: a primeira propõe o espaço aberto entre as edificações como continuidade da calçada, criando edifícios em forma de lâminas ou torres recuadas no interior das quadras, a segunda propõe quadras urbanas fechadas por edifícios novos justapostos aos existentes, configurando uma ocupação no perímetro das quadras. A avaliação do desempenho ambiental das duas tipologias foi realizada através da combinação de estudos analíticos apoiados por simulações computacionais que avaliaram diferentes parâmetros de ventilação urbana, conforto térmico, acústico e luminoso, além de questões de acessibilidade e segurança.

A avaliação de desempenho ambiental como parte do processo de desenho urbano mostrou-se uma importante ferramenta na discussão sobre o tema das cidades mais compactas e com melhor qualidade de vida, observada no início da década de 1990, 
em diferentes contextos urbanos do cenário internacional, fornecendo parâmetros fundamentais para a tomada de decisão sobre a tipologia e arranjo espacial das novas edificações projetadas sobre a cidade existente (MIANA, 2010).

Nas duas opções de adensamento, a repetição do padrão urbanístico permitiu a criação de diversas áreas verdes na escala da quadra ${ }^{5}$, mais favoráveis ao microclima urbano e ao conforto do pedestre, do que uma única área verde de dimensões que vão além daquelas da quadra urbana. A esse respeito, é importante considerar que o efeito da vegetação é local e não influencia significativamente áreas muito além dos limites das áreas verdes (SHINZATO, 2009).

Por decisão metodológica estratégica, a elaboração de objetivos e diretrizes para os espaços livres e áreas verdes abordada nesta parte do trabalho foi realizada para a tipologia que propõe a ocupação no perímetro da quadra (ver figura 3), onde os espaços livres concentram-se no interior das quadras.

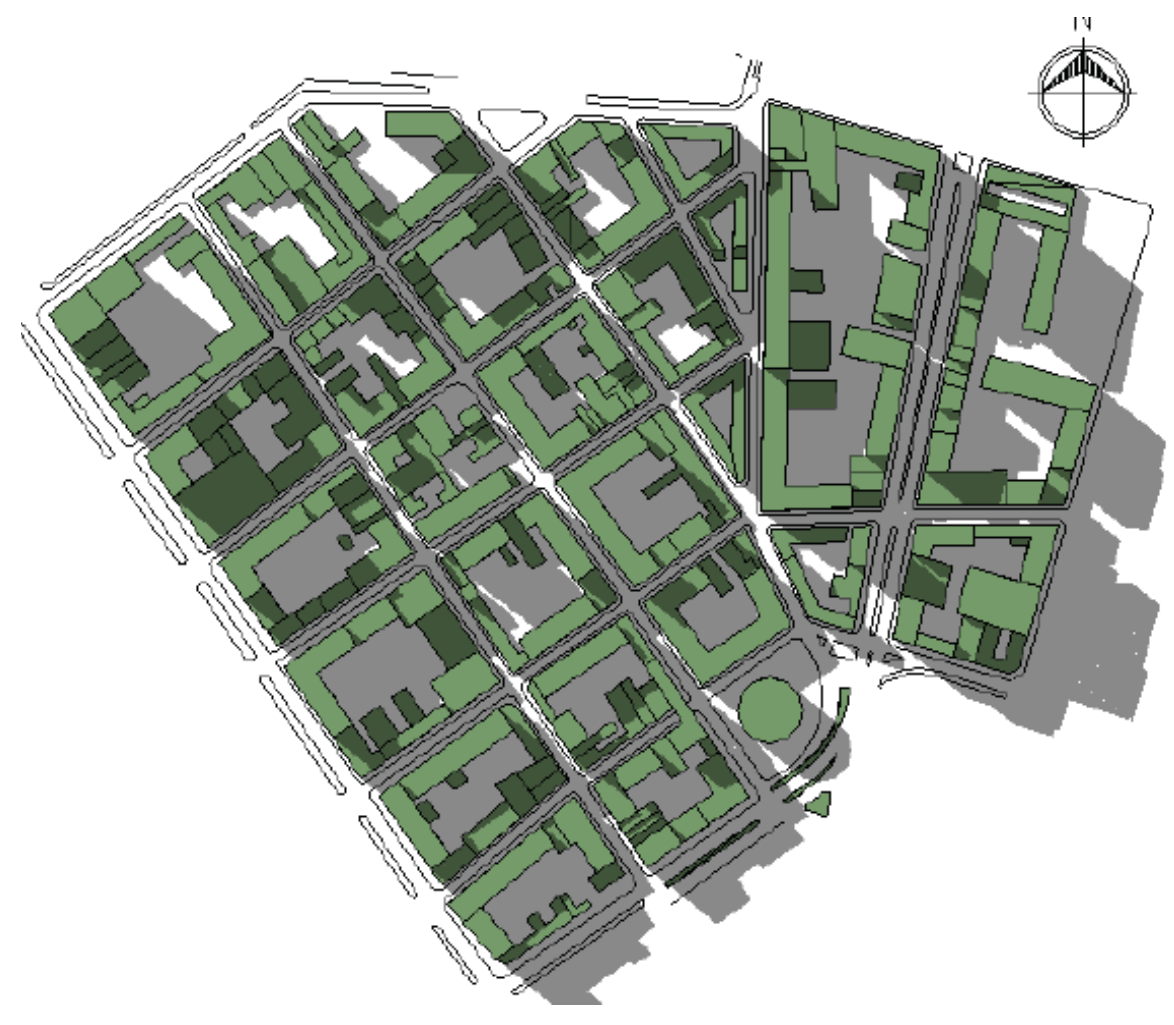

Figura 3 - Nova proposta de tipologia de desenho urbano escolhida para a presente pesquisa, caracterizada por quadras urbanas fechadas por edifícios novos, justapostos aos existentes, configurando uma ocupação no perímetro das quadras.

\footnotetext{
${ }^{5}$ Entende-se por "escala da quadra", trabalhar com o desenho urbano em dimensões mínimas de quadra, tendo esta como unidade de planejamento.
} 


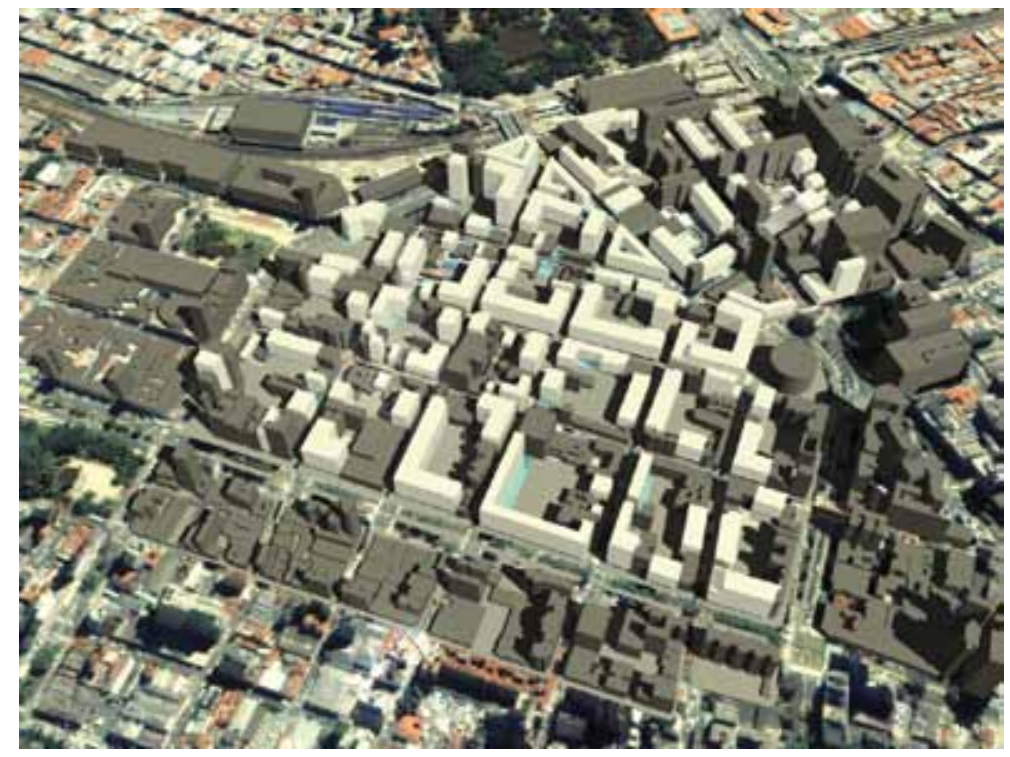

Figura 4 - Perspectiva da tipologia de desenho urbano escolhida para a pesquisa, configurando uma ocupação no perímetro das quadras. Os edifícios em cinza são os existentes e os brancos são os novos edifícios propostos.

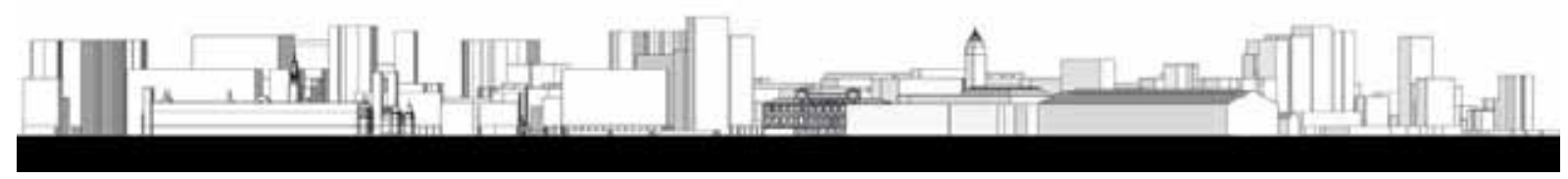

Figura 5 - Vista da tipologia de implantação desenho urbano escolhido por essa pesquisa.

\section{OBJETIVOS DO PROJETO DAS NOVAS ÁREAS LIVRES}

(1) Diversificar e ampliar a oferta de áreas de lazer próximo às áreas de trabalho e moradia;

Uma das preocupações do adensamento das edificações de uso misto é a oferta de espaços de lazer tanto para a população residente como para a população que trabalha ou frequenta a área. Assim, uma das diretrizes do projeto foi o aproveitamento das esquinas, das áreas entre os edifícios e das áreas no interior das quadras. Tal solução só é possível quando a unidade de planejamento e projeto é a própria quadra. Com a eliminação do lote, as áreas entre os edifícios puderam ser melhor aproveitadas e as áreas no interior das quadras puderam ser acessadas com maior facilidade transformando-se em importantes espaços livres de uso público. 
(2) Melhorar a qualidade do percurso de pedestres e ciclistas considerando a segurança, a acessibilidade e o conforto ambiental;

O aporte significativo do número de unidades habitacionais proposto pelo projeto de intervenção coordenado pelo Labaut e as características de uso e ocupação do bairro propiciam um intenso fluxo de pedestres e veículos. Somado a isso tem-se a introdução de uma modalidade de transporte não existente na área hoje, a bicicleta. Assim, o projeto das novas áreas livres buscou elevar a qualidade ambiental do percurso de pedestres e ciclistas, por meio do aumento da diversidade de trajetos $\mathrm{e}$ áreas de lazer, e melhorar o microclima local com o uso estratégico da vegetação.

A vegetação pode contribuir com diversos aspectos ambientais nas cidades, interferindo na temperatura e na umidade, na drenagem, na estabilização do solo, na fixação de partículas suspensas na atmosfera, etc. Porém, vale ressaltar que não é qualquer tipo vegetação plantada em qualquer local que contribui com os itens citados. Além disso, os aspectos ambientais devem ser pensados conjuntamente com os sociais, para que os benefícios climáticos da vegetação não se convertam em problemas para a população.

Uma área densamente vegetada pode oferecer problemas de segurança em grandes aglomerados urbanos. Dependendo da espécie, as raízes de uma árvore podem danificar construções e oferecer riscos às pessoas. Áreas que estão sombreadas constantemente pelas edificações devem receber um tratamento paisagístico diferenciado, com espécies adequadas e pouca cobertura arbórea, inclusive para o conforto ambiental do pedestre. Assim, a escolha das espécies vegetais e da densidade de plantio buscou contextualizar a paisagem local, analisando os fluxos de pedestres e veículos e os espaços livres, procurando maximizar os benefícios socioambientais da vegetação no meio urbano.

\section{(3) Melhorar as condições de drenagem da área;}

Os problemas em relação à drenagem urbana são uma constante da cidade de São Paulo e a área da Luz não é uma exceção. Ocupação de várzeas, retificação e canalização de rios e córregos e os altos níveis de supressão de vegetação e impermeabilização do solo são alguns dos fatores que contribuem para as constantes enchentes na cidade. Apesar de a área de estudo apresentar poucos pontos críticos de drenagem e inundação, entende-se que estes problemas nem sempre são gerados no local onde ocorrem, sendo necessário que todas as intervenções 
urbanas contemplem tais questões para que não contribuam com o agravamento do problema a jusante.

O aumento de área permeável e o aumento da cobertura arbórea por si só já configuram estratégias que beneficiam a drenagem urbana, pois aumentam a infiltração de água no solo e a interceptação pela copa das árvores. Porém, pelo fato do solo da região ser argiloso, dependendo da intensidade das chuvas, a capacidade de absorção deste não é suficiente para evitar enchentes, por isso foram previstas estruturas de armazenamento temporário das águas pluviais. Tais estruturas, jardins de chuva ou biovaletas, poderão estar localizados nos passeios, quando sua largura permitir, nas áreas de convivência entre os edifícios ou em jardins no interior das quadras.

\section{(4) Aumentar a diversidade de habitat para a fauna.}

Tendo em vista a proximidade com o Parque da Luz, uma das preocupações do projeto foi a conexão entre as áreas verdes propostas e as existentes no bairro, estratégia particularmente importante para a fauna. No caso do Parque da Luz, o último inventário, publicado em 2010 pela Secretaria do Verde e do Meio Ambiente (SVMA), mostrou que o Parque conta com 73 espécies distintas, sendo 67 somente de aves. Das 73 espécies levantadas, 14 foram consideradas espécies mundialmente ameaçadas segundo a Convention on International Trade in Endangeres Species of Wild Fauna and Flora 2009. Assim, a conexão entre as áreas verdes e o enriquecimento arbóreo do bairro com espécies nativas que beneficiem a fauna, tanto em abrigo como em alimento, possibilitam o aumento da diversidade e número de indivíduos de tais espécies.

O enriquecimento arbóreo proposto considera o plantio nos passeios, quando estes apresentarem largura adequada, e nos demais espaços livres da quadra urbana. Em determinadas áreas propõe-se a criação de maciços de vegetação mais densos chamados neste estudo de "bolsões de diversidade", que desempenham o papel de trampolins ecológicos ${ }^{6}$, além do adensamento da vegetação existente nos canteiros centrais das avenidas, formando corredores verdes.

\footnotetext{
${ }^{6}$ Segundo Conselho Nacional Reserva da Biosfera da Mata Atlântica , trampolins ecologicos são "áreas estratégicas que funcionam como "ilhas" e podem tanto facilitar o fluxo gênico de espécies que transitam por uma matriz não florestal quanto ajudar no planejamento e implementação de corredores biológicos. Em alguns casos, ajudam a aumentar a representatividade de algumas unidades de paisagem. Disponivel em : http://www.rbma.org.br/anuario/mata_06_fap_capitulo_5_pag3.asp. Acesso em : junho/2012.
} 
O quadro abaixo sintetiza os objetivos do projeto e as diretrizes adotadas pelo projeto paisagístico.

Tabela 1 - Síntese dos objetivos e das diretrizes de projeto

\begin{tabular}{|l|l|}
\hline \multicolumn{1}{|c|}{ Objetivos } & \multicolumn{1}{|c|}{ Diretrizes de projeto } \\
\hline $\begin{array}{l}\text { Diversificar e ampliar a oferta de áreas } \\
\text { de lazer }\end{array}$ & $\begin{array}{l}\text { Aproveitamento das esquinas, das } \\
\text { áreas entre os edifícios e no interior } \\
\text { das quadras. }\end{array}$ \\
\hline $\begin{array}{l}\text { Melhorar a qualidade do percurso de } \\
\text { pedestres e ciclistas }\end{array}$ & $\begin{array}{l}\text { Diversificar trajetos e utilizar estrategi- } \\
\text { camente a vegetação visando a segu- } \\
\text { rança e o conforto ambiental. }\end{array}$ \\
\hline Melhorar as condições de drenagem & $\begin{array}{l}\text { Aumentar a área permeável e criar es- } \\
\text { truturas de armazenamento temporário } \\
\text { das águas pluviais. }\end{array}$ \\
\hline $\begin{array}{l}\text { Aumentar a diversidade de habitat para } \\
\text { a fauna. }\end{array}$ & $\begin{array}{l}\text { Promover a conexão entre as áreas } \\
\text { verdes existentes e as novas; Prever } \\
\text { o enriquecimento arbóreo com espé- } \\
\text { cies nativas. }\end{array}$ \\
\hline
\end{tabular}

\section{MÉTODO}

A definição das estratégias de infraestrutura verde a serem aplicadas nos espaços livres resultantes da tipologia de ocupação perimetral descrita no item anterior, baseouse na caracterização dessas áreas quanto à sua localização,dimensão, uso do solo, fluxo de pedestres e ciclistas; e de sua insolação. O cruzamento dessas informações permitiu definir a vocação das áreas livres como áreas verdes de passagem ou permanência. Essa avaliação foi dividida em 4 etapas descritas a seguir:

Etapa 1. Identificação, mapeamento e avaliação qualitativa das áreas verdes existentes no bairro e da possibilidade de conectá-las com as novas áreas verdes propostas através de corredores verdes. 
Etapa 2: Avaliação qualitativa do fluxo de pedestres a partir da nova proposta de desenho urbano, considerando-se as possibilidades de percurso e os tipos de usos do solo propostos aliados aos usos existentes, identificando assim, as possíveis rotas para os pontos de concentração de pessoas (eixo de transporte e estações de trem e metrô, ruas comerciais, parques, museus, feiras, etc.).

Etapa 3: Avaliação da insolação do conjunto, inclusive nos espaços livres, por meio de simulações computacionais (com o uso do software Ecotect ${ }^{7}$ ) nos solstícios de inverno e de verão, das $8 \mathrm{~h}$ às $18 \mathrm{~h}$. As áreas que apresentaram 5 ou mais horas de insolação no verão ou no inverno, ou em ambas as épocas do ano, foram classificadas como áreas ensolaradas. O resultado do estudo da insolação foi um importante critério para definição de diretrizes de especificação e caracterização da vegetação, inclusive quanto seu porte e densidade.

Os resultados são obtidos a partir do cruzamento dos dados de uso do solo e fluxo de pedestres com os resultados de insolação, a fim de propor novos espaços livres de acordo com sua vocação como locais de passagem ou de permanência e quanto à vocação para potencializar o aumento da biodiversidade local.

\subsection{ETAPA 1. IDENTIFICAÇÃO, MAPEAMENTO E AVALIAÇÃO QUALITATIVA DAS ÁREAS VERDES EXISTENTES NO BAIRRO E DA POSSIBILIDADE DE CONECTÁ-LAS COM AS NOVAS ÁREAS VERDES PROPOSTAS ATRAVÉS DE CORREDORES VERDES.}

Para a implantação dos corredores verdes foram escolhidas avenidas e ruas que comportassem um adensamento de plantio arbóreo significativo, capaz de configurar o corredor. Assim, pelo fato de a maioria das calçadas da região ser muito estreita, optou-se por avenidas que apresentassem canteiros centrais, de forma que o adensamento da vegetação não comprometesse a circulação de pedestres. Os corredores das avenidas Cásper Líbero e Duque de Caxias - Rua Mauá foram os escolhidos, ligando importantes áreas verdes, como a Praça Princesa Isabel, Largo do Arouche e Praça da República ao Parque da Luz, como pode-ser visto na imagem esquemática a seguir.

\footnotetext{
${ }^{7}$ MARSH and RAINES,2004.
} 


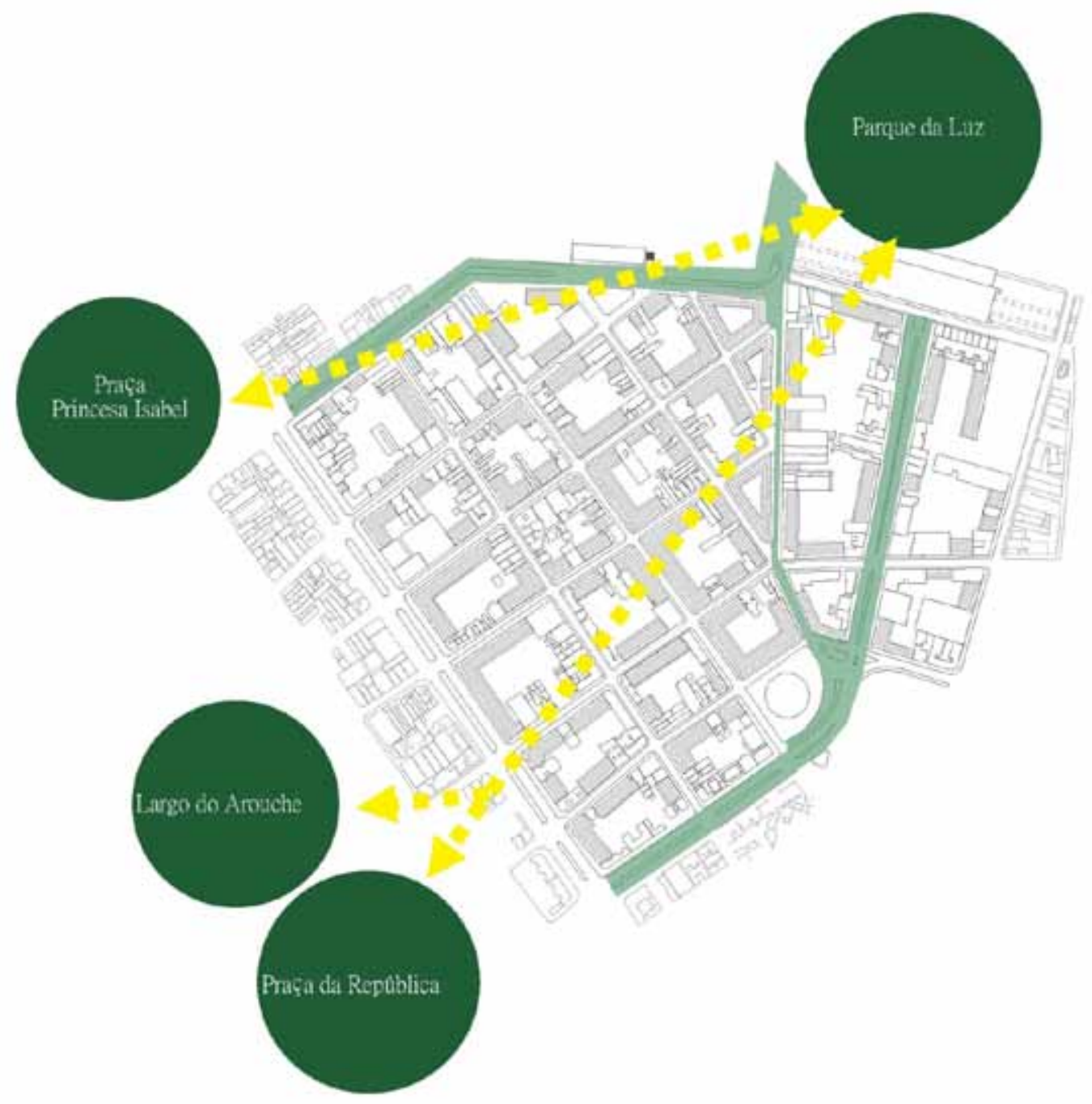

Figura 6 - Conexões ecológicas - corredores verdes.

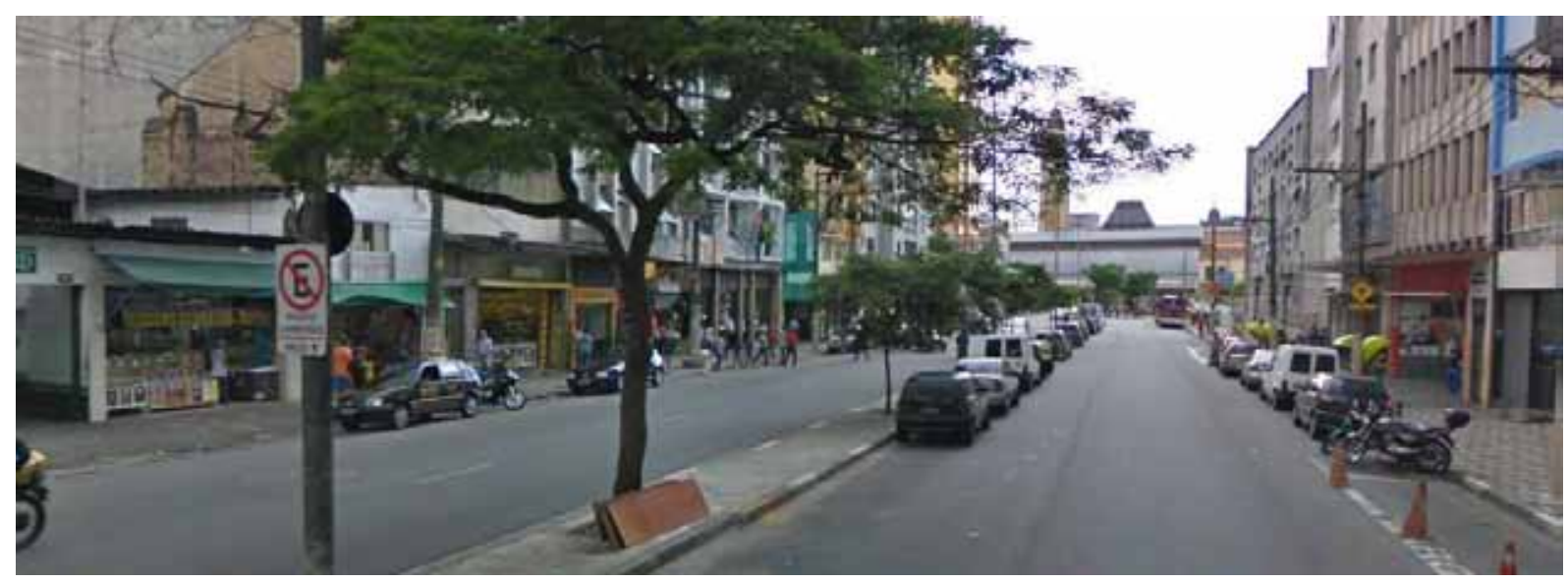

Figura 7 - Canteiro central Av. Cásper Líbero que pode ser enriquecido com espécies arbóreas nativas, constituindo um corredor verde. Fonte: Google 


\subsection{ETAPA 2. AVALIAÇÃO QUALITATIVA DO FLUXO DE PEDESTRES A PARTIR DA NOVA PROPOSTA DE DESENHO URBANO}

A avaliação das diversas possibilidades de percursos peatonais gerou sua classificação em dois tipos, o fluxo perimetral e o fluxo intra-quadra, divididos em três níveis de intensidade: alto, médio e baixo. A imagem a seguir sintetiza a avaliação do fluxo de pedestres realizada.

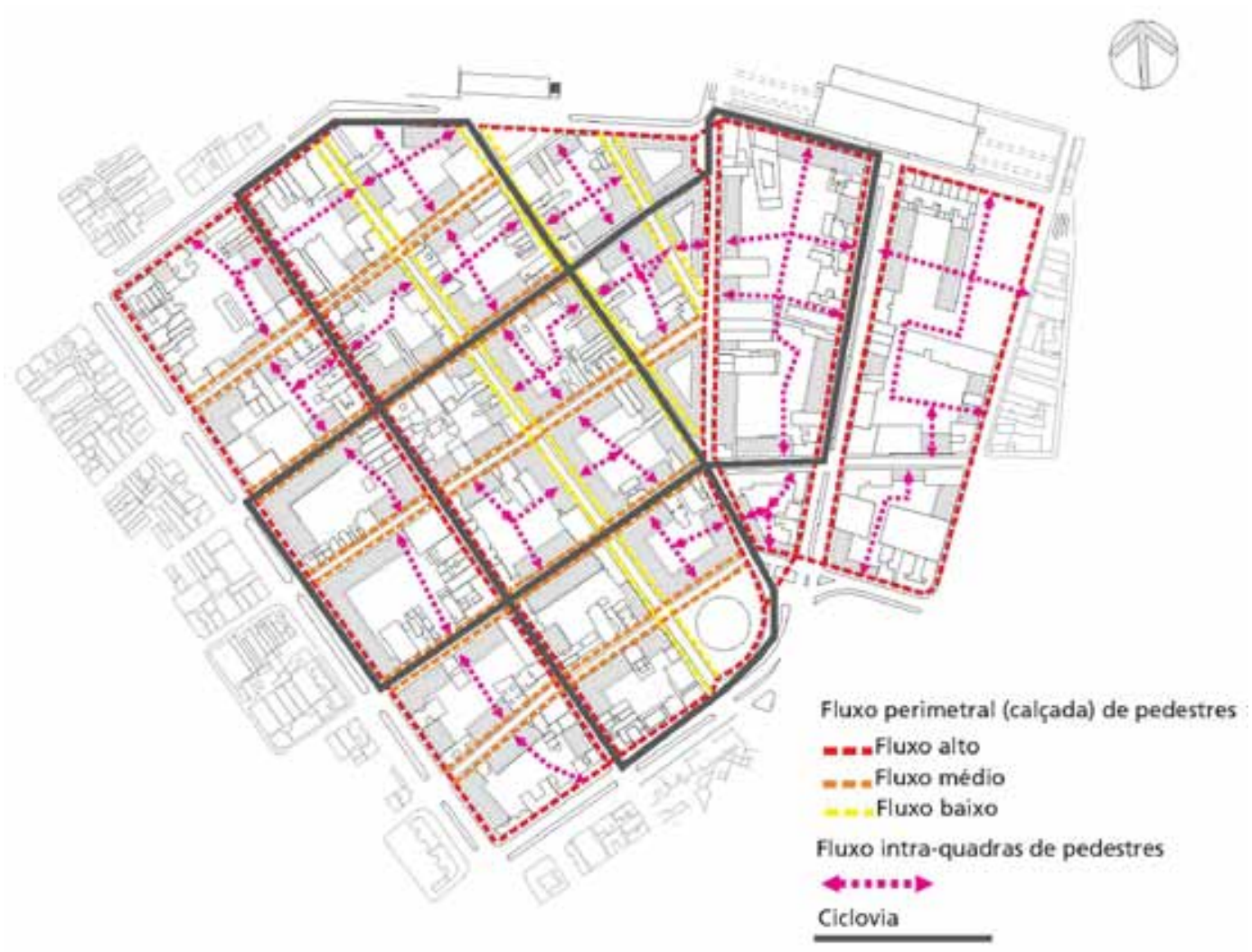

Figura 8 - Classificação dos fluxos de pedestres e ciclistas. Configuração perímetro.

\subsection{ETAPA 3: AVALIAÇÃO DA INSOLAÇÃO DO CONJUNTO.}

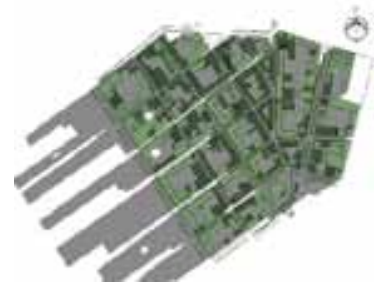

$8 \mathrm{~h}$

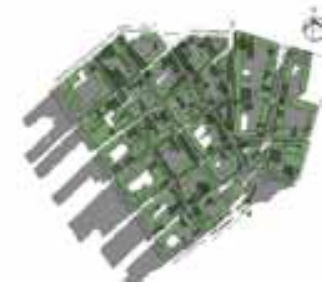

$9 \mathrm{~h}$

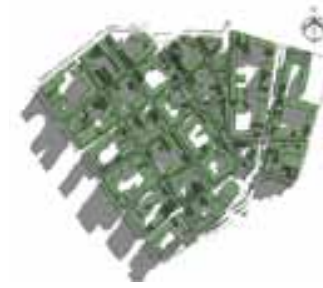

$10 \mathrm{~h}$

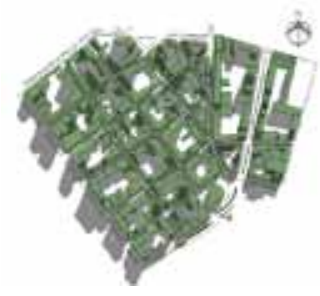

$11 \mathrm{~h}$

Figura 9 - Exemplo da análise de insolação realizada. Solstício de inverno (21 de junho) das 8 às $11 \mathrm{~h}$. 


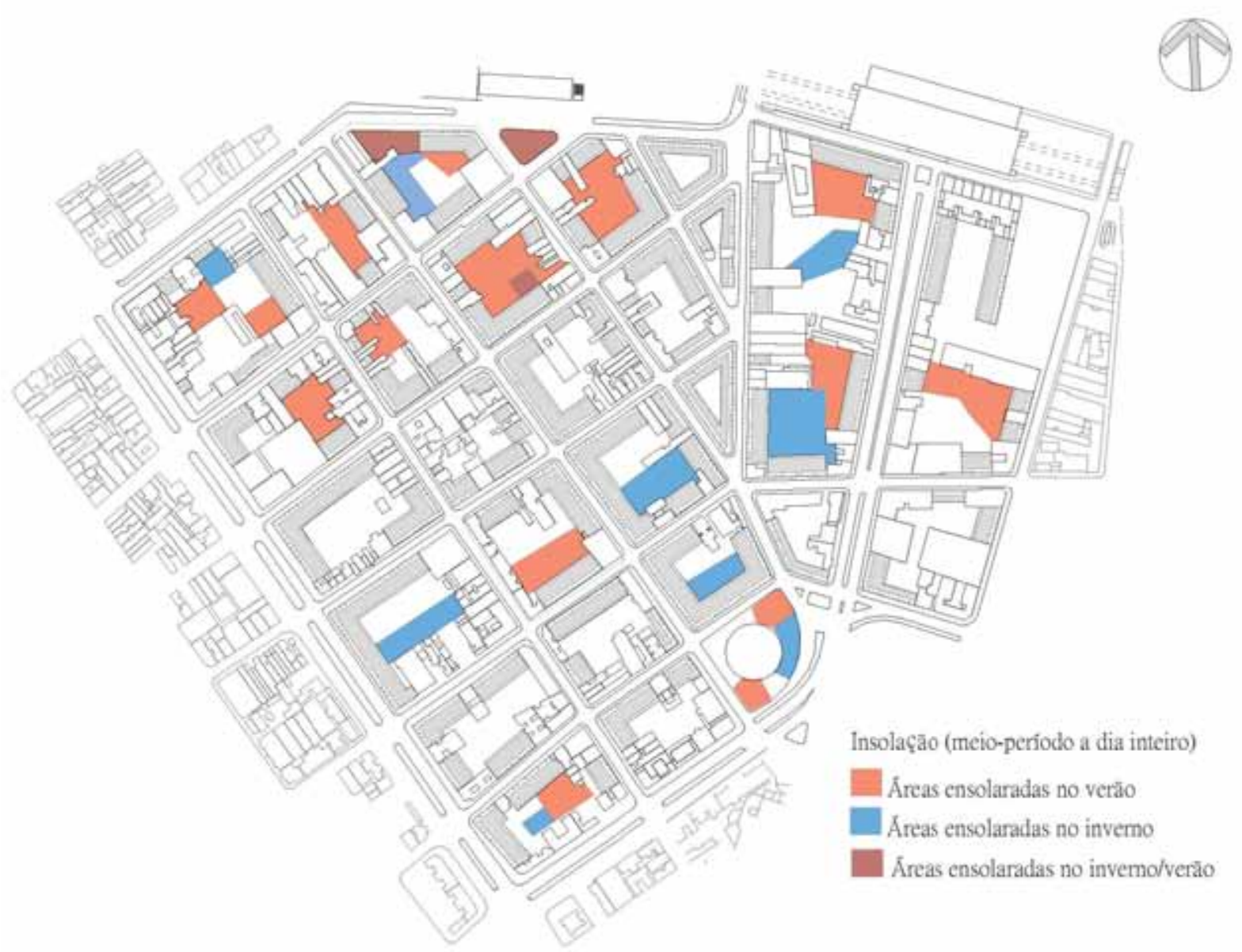

Figura 10 - Classificação da insolação da área. Configuração perímetro.

Todas as áreas livres foram analisadas nos solstícios de inverno e de verão, das $8 \mathrm{~h}$ às $18 \mathrm{~h}$, sendo classificadas como ensolaradas no verão, no inverno, ou em ambas as épocas do ano quando apresentaram 5 ou mais horas de incidência de radiação solar direta nos dias estudados.

O número de horas de insolação foi um fator importante na definição do porte e densidade da vegetação a ser implantada nas áreas de estar, como descrito anteriormente. Como diretriz de projeto definiu-se que as áreas que recebem muitas horas de sol no verão devem ser sombreadas, proporcionando maior conforto aos pedestres. Pelo mesmo motivo as áreas que apenas recebem sol no inverno não devem receber sombreamento e as áreas que recebem insolação nas duas estações, devem estar protegidas e sombreadas no verão e permitir a incidência de sol no inverno. 


\section{RESULTADOS}

\subsection{AVALIAÇÃO DA VOCAÇÃO DE USO DOS ESPAÇOS LIVRES COMO LOCAIS DE PERMANÊNCIA OU PASSAGEM.}

Foram consideradas como locais de passagem as áreas demarcadas pelas linhas pontilhadas na figura 8 . Os demais espaços livres foram considerados como locais potenciais de maior permanência e convívio.

Locais de passagem: sempre que possível deveriam apresentar vegetação arbórea, tanto nas calçadas como nas áreas internas às quadras. Poderiam também apresentar uma combinação entre vegetação arbórea, arbustiva e herbácea. Houve um cuidado e atenção maior na especificação e localização da vegetação arbustiva, levando-se em conta a questão da segurança do pedestre e visibilidade do ciclista e a vegetação herbácea quanto à possibilidade de pisoteio.

Locais de permanência: nas áreas de permanência ensolaradas no inverno foi proposta vegetação herbácea e arbustiva. Como não há abundância desse tipo de área no bairro, tomou-se o cuidado de garantir a insolação nessas áreas evitando-se vegetação de porte arbóreo.

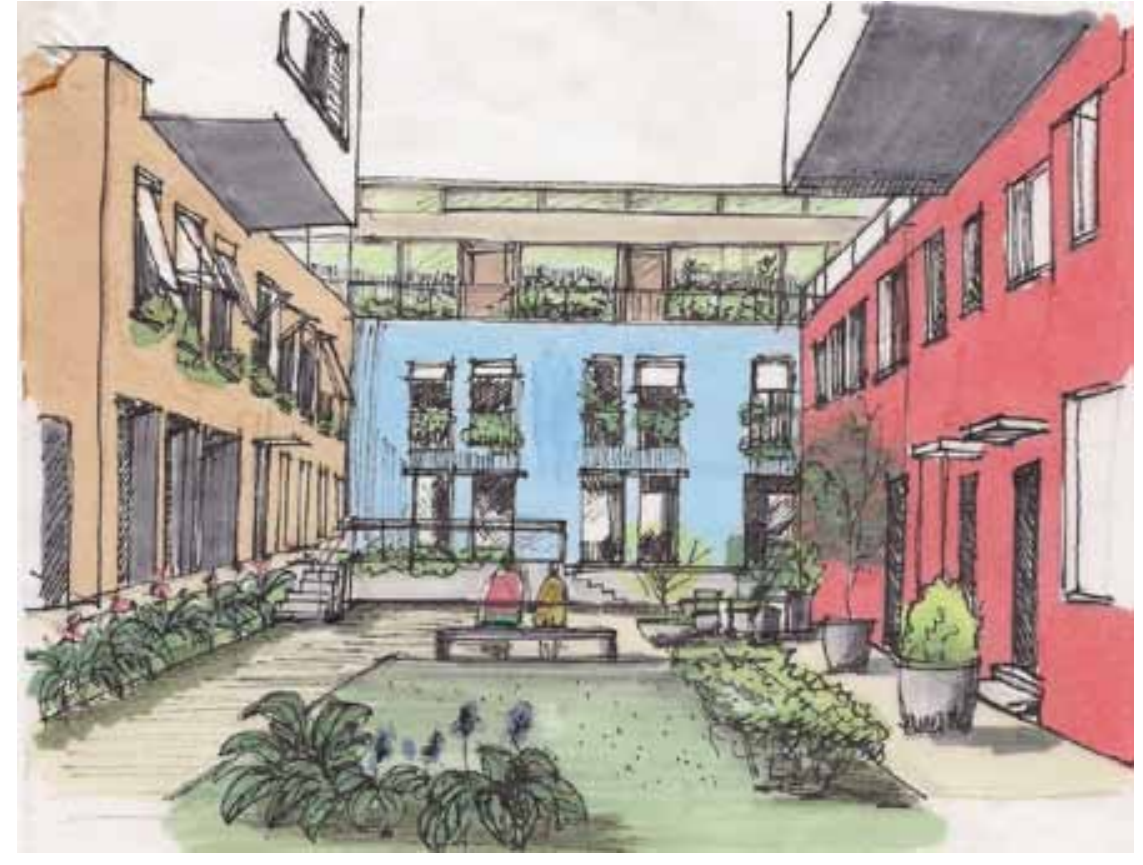

Figura 11 - Ilustração de um local de permanência ensolarado no inverno com predominância de vegetação arbustiva e herbácea. 
Nas áreas ensolaradas no verão foi proposta uma combinação entre vegetação herbácea, arbustiva e arbórea.

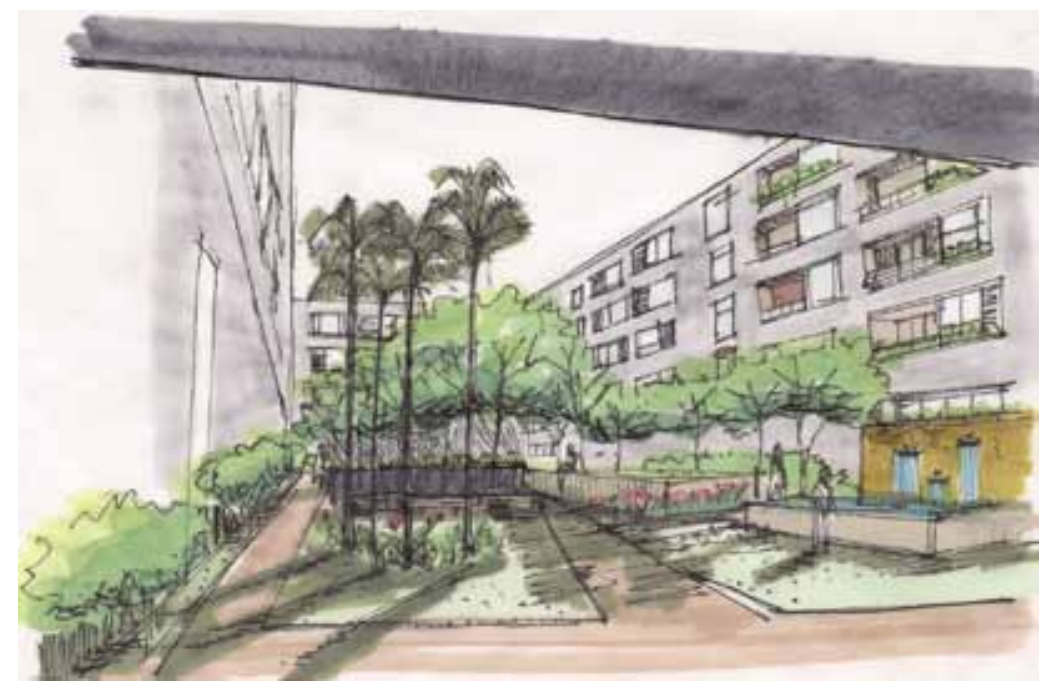

Figura 12 - llustração de um local de permanência ensolarado no verão com vegetação arbustiva, herbácea e arbórea.

Nas áreas ensolaradas tanto no inverno quanto no verão foi proposta a mesma combinação, porém, com espécies arbóreas caducifólias, permitindo sombreamento no verão e insolação direta no inverno.

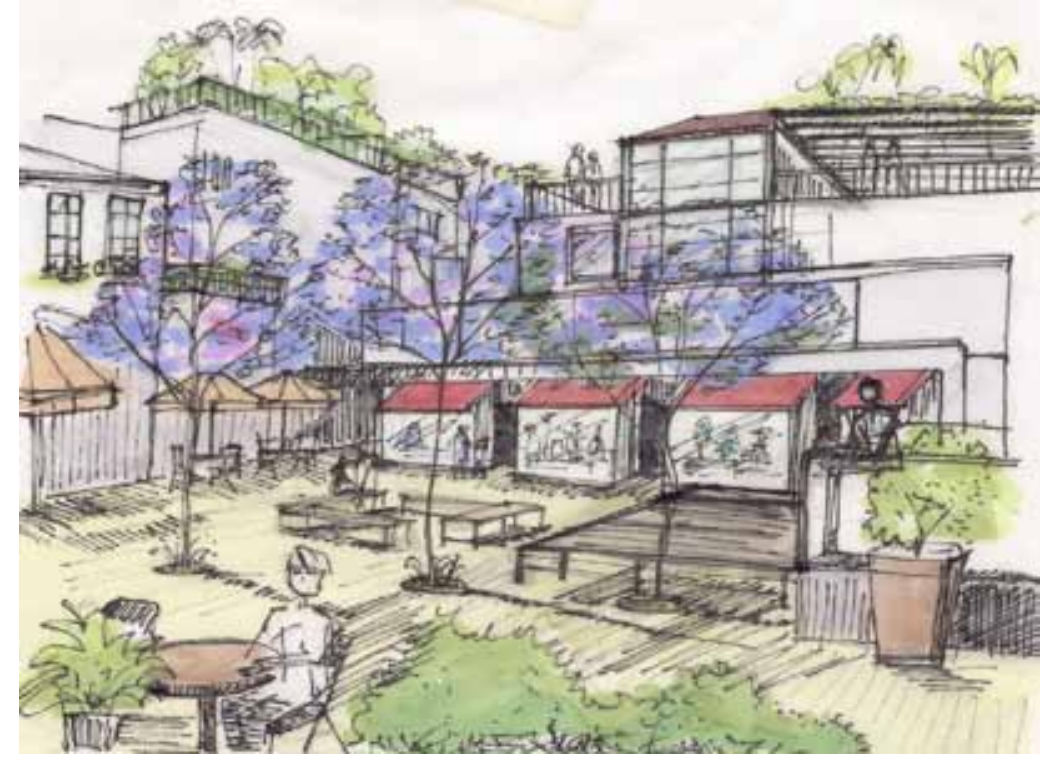

Figura 13 - llustração de um local de permanência ensolarado tanto no verão quanto no inverno, com espécies arbóreas caducifólias, como, por exemplo, o ipê-roxo.

O anexo 1 sugere algumas espécies adequadas a cada situação. Por fim, o estudo aqui apresentado evidencia a possibilidade de aliança entre o aumento de densidade populacional e o incremento quantitativo e qualitativo das áreas verdes na área da Luz. 


\subsection{PROPOSIÇÕES PARA BIOVERSIDADE: BOLSÕES DE VEGETAÇÃO COMO TRAMPOLINS ECOLÓGICOS}

Além dos corredores verdes sugeridos em locais estratégicos em virtude das áreas verdes existentes, a partir na nova morfologia e desenho urbano de áreas construídas e livres, foram propostos os bolsões de diversidade, entendidos, sob a ótica da Ecologia da Paisagem, como trampolins ecológicos, auxiliando no fluxo de espécies e genes entre as manchas de vegetação existentes. Eles foram determinados, a partir das novas áreas verdes propostas, na qual a intensidade dos fluxos foi uma variável mais significativa do que a insolação. Considerando-se que esses espaços foram conceituados como áreas de vegetação densa (com bosque e sub-bosque), por questões de segurança, sua implantação seria mais adequada em áreas de acesso restrito, configurando, por exemplo, espaços de lazer condominiais.

Os bolsões de diversidade consistem na restauração ecológica, a partir da combinação de espécies arbóreas pioneiras, secundárias iniciais, secundárias tardias e climáxicas, aliado ao enriquecimento futuro de espécies arbustivas e herbáceas para a formação de um sub-bosque. As espécies arbóreas mais sensíveis ou de desenvolvimento lento (climáxicas) deverão estar sempre envoltas das espécies pioneiras (de crescimento rápido) e secundárias iniciais de forma a proporcionar sombreamento. Estima-se a utilização de 30 espécies distintas ${ }^{8}$, algumas delas listadas na tabela 2 apresentada no anexo 1.

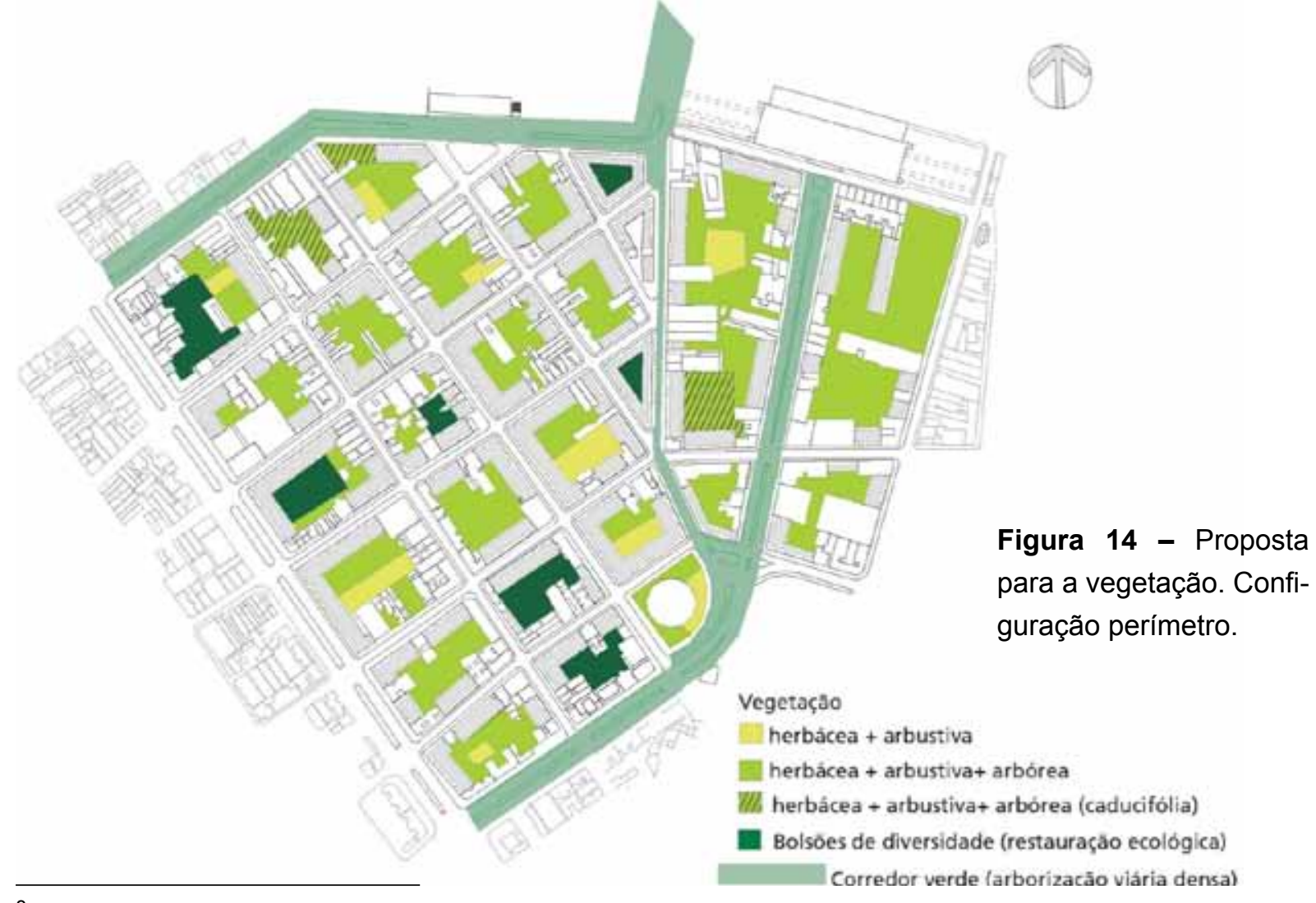

\footnotetext{
${ }^{8}$ De acordo com o previsto na Resolução SMA $n^{\circ} 47$ que trata sobre o reflorestamento heterogeneo para áreas de até 1 hectare.
} 


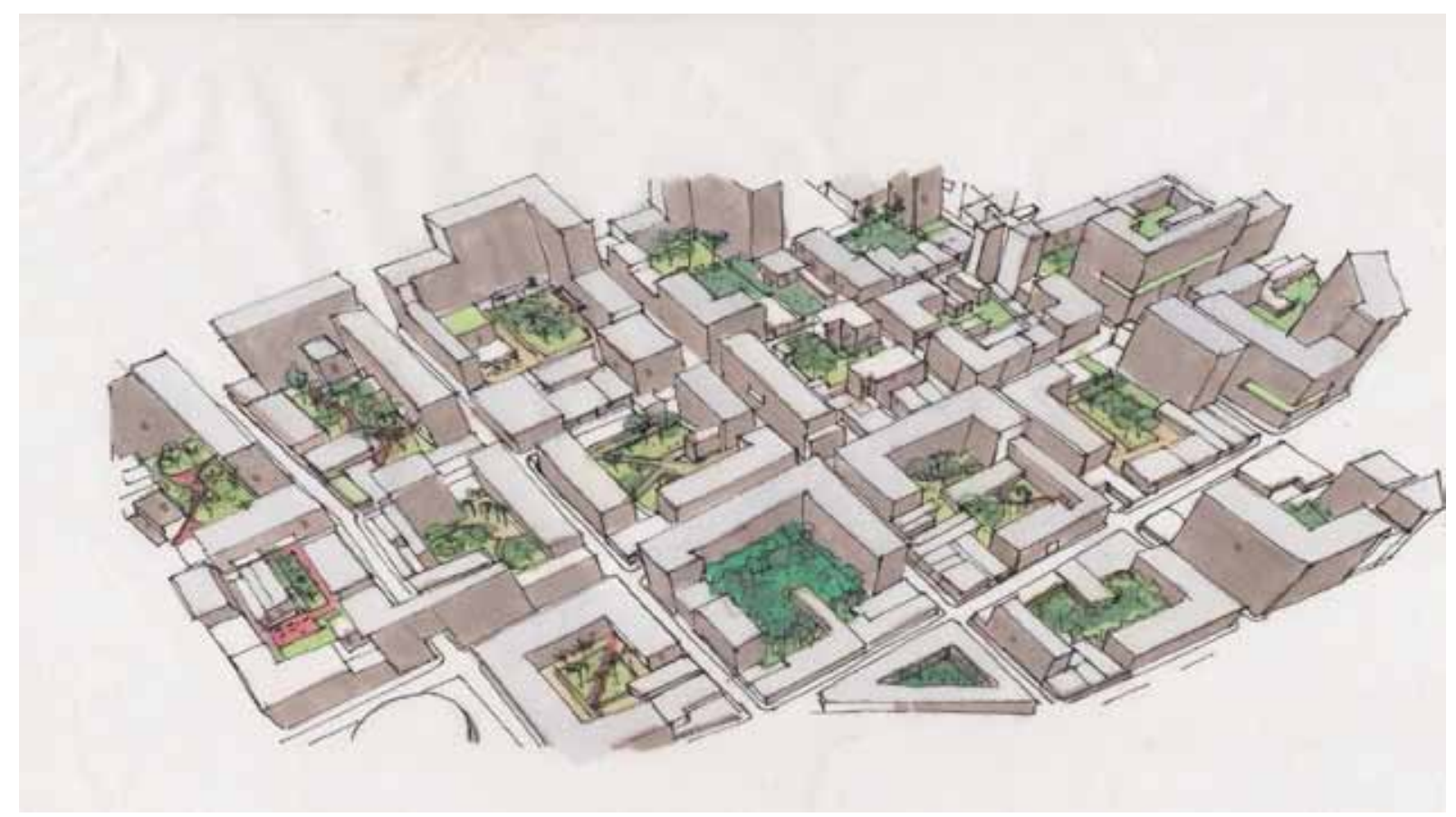

Figura 15 - llustração síntese dos espaços verdes propostos nas áreas internas das quadras.

\section{CONSIDERAÇÕES FINAIS}

Como mencionado anteriormente, a pesquisa insere conceitos, objetivos e diretrizes ainda pouco abordados nos projetos paisagísticos em escala urbana, sendo sua aplicação prática verificada através do estudo de caso da área da Luz, no Bairro de Santa Efigenia. Tal região caracteriza-se por ser adensada construtivamente, porém, pouco densa demograficamente, com baixo aproveitamento da rica infraestrutura em face do número reduzido de unidades habitacionais existentes. Assim, identificada a possibilidade de adensamento populacional na região, tornam-se fundamentais o aumento da quantidade de espaços públicos e áreas verdes qualificadas.

O primeiro passo para a viabilização deste objetivo foi considerar a quadra, e não o lote, como unidade mínima de planejamento e projeto urbano, oferecendo, assim, uma gama maior de possibilidades de desenho e interação das áreas livres com os ambientes construídos.

Os quatro principais objetivos do projeto: oferta de espaços livres, qualidade ambiental para o pedestre, drenagem e biodiversidade, bem como suas diretrizes, apresentam uma aplicabilidade que extrapola os limites da área da Luz e podem ser úteis como 
primeiro direcionamento de projeto para outras situações urbanísticas similares, sempre considerando, obviamente, as particularidades e o contexto da paisagem local. $O$ mapa da distribuição das áreas verdes resultante revela a vocação de cada espaço livre para o conforto ambiental do pedestre, o tipo de vegetação mais adequada quanto ao porte, densidade e perenidade de suas folhas.

Quantitativamente verificou-se um aumento de $1200 \%$ das áreas verdes em comparação à configuração da morfologia urbana e desenho atual do bairro. A configuração atual apresenta $5.033 \mathrm{~m}^{2}$ de área livre vegetada, considerando-se praças, canteiros e pátios internos com vegetação. A configuração proposta apresenta $60.450 \mathrm{~m}^{2}$ de área livre vegetada e permeável, representando um aumento de 12 vezes. Se incluirmos neste valor áreas de estar e passeios tem-se $86.360 \mathrm{~m}^{2}$ de área livre. Qualitativamente o incremento deve-se à criteriosa distribuição da vegetação nas áreas livres e à escolha das espécies, priorizando questões como conectividade ecológica, mobilidade, drenagem das águas pluviais, conforto ambiental para o pedestre e oferta de espaços de lazer.

Ressalta-se que o aumento da quantidade de áreas verdes deu-se em um contexto de aumento da densidade populacional e construtiva proposto pelo projeto multidisciplinar coordenado pelo Labaut, demonstrando a possibilidade de aumento de densidade com aumento da área vegetada.

Assim, a pesquisa estimula a visão crítica, visando alterar ideias ou conceito preconcebidos de que a alta densidade está vinculada a qualidade urbanística ruim, destituídas de áreas verdes.

Diante da carência de áreas verdes em muitas cidades brasileiras, ao apresentar diretrizes de projeto factíveis aos grandes centros urbanos, esta pesquisa pretende servir como ponto de referência para a implantação de novas áreas vegetadas públicas e privadas de forma criteriosa, atentando-se para especificidades climáticas e socioeconômicas locais. 


\section{REFERÊNCIAS BIBLIOGRÁFICAS}

COURMIER, N. Green Infrastructure: high performance landscapes for healthy cities. In: Discussão sobre inserção do verde e drenagem urbana sustentável. SABESP, São Paulo, 2008.

GONÇALVES, Joana C. S.; MULFARTH, Roberta K.; MONTEIRO, Leonardo M.; MOURA, Norberto C.; PRATA, Alessandra R.; MIANNA, Anna C., CAVALCANTE, Rodrigo. Adensamento Urbano e Desempenho Ambiental no Centro da Cidade de São Paulo. XI ENCAC, VII ELACAC. Buzios, Rio de Janeiro: ANTAC, 2011.

JOHNSTON, J. Nature areas for city people. Ecology Handbook n.14 London Ecology Unit. 1990

LORENZI, H. Árvores brasileiras: manual de identificação e cultivo de plantas arbóreas nativas do Brasil vol. 1. Nova Odessa: Plantarum, 2002.

LORENZI, H. Árvores brasileiras: manual de identificação e cultivo de plantas arbóreas nativas do Brasil vol. 2. Nova Odessa: Plantarum, 2002.

LORENZI, H; SOUZA, H. Plantas Ornamentais no Brasil - Arbustivas, herbáceas e trepadeiras. 3 ed. Nova Odessa, São Paulo: Instituto Plantarum, 2001.

MARSH, A.; RAINES, C..Ecotect v.5.20. Square One; Joondalup: Austrália, 2004.

MIANA, Anna Christina. Adensamento e forma urbana : inserção de parâmetros ambientais no processo de projeto. Tese (Doutorado) - Faculdade de Arquitetura e Urbanismo da Universidade de São Paulo (FAUUSP). São Paulo. 2010.

PELLEGRINO, P. R. M.; GUEDES, P.P.; PIRILO. F. C.; FERNANDES, S. A. Paisagem da borda: uma estratégia para a condução das águas, da biodiversidade e das pessoas. In: Costa, Lucia M. S. A. (Org.). Rios e paisagem urbana em cidades brasileiras. 1ed. Rio de Janeiro: Viana \& Mosley Editora/Editora PROURB, 2006, v.1, p. 57-76.

SANCHES, P. M. De áreas degradadas a espaços vegetados: potencialidades de áreas vazias, abandonadas e subutilizadas como parte da infra-estutura verde urbana. Dissertação de mestrado, Faculdade de Arquitetura e Urbanismo da Universidade de São Paulo São Paulo, 2011.

SÃO PAULO (Cidade). SECRETARIA MUNICIPAL DO VERDE E DO MEIO AMBIENTE. 
Inventário da Fauna do Município de São Paulo, 2010. Disponível em: http://www. prefeitura.sp.gov.br/cidade/secretarias/meio_ambiente/publicacoes_svma/index. php?p=4162. Acesso em 15/10/2010.

SÃO PAULO (Cidade). SECRETARIA MUNICIPAL DO VERDE E DO MEIO AMBIENTE. Manual técnico de arborização urbana. São Paulo: SVMA, 2005. Disponível em: http://www.prefeitura.sp.gov.br/cidade/secretarias/meio_ambiente/publicacoes_svma/ index.php?p=3351. Acesso em 15/10/2010.

SHINZATO, P. O impacto da vegetação nos microclimas urbanos. Dissertação de mestrado, Faculdade de Arquitetura e Urbanismo da Universidade de São Paulo. São Paulo, 2009.

\section{AGRADECIMENTOS}

À Fundação de Amparo à Pesquisa do Estado de São Paulo - FAPESP, à Coordenação de Aperfeiçoamento de pessoal de Nível Superior - CAPES pelo apoio durante a realização da pesquisa. 


\section{ANEXO 1}

Tabela 2 - Espécies indicadas de acordo com local de plantio.

\begin{tabular}{|c|c|c|c|}
\hline Local de utilização & Nome científico & Nome popular & $\begin{array}{c}\text { Estagio } \\
\text { sucessional }\end{array}$ \\
\hline $\mathrm{CA}, \mathrm{CV}, \mathrm{BD}, \mathrm{PV}$ & Caesalpinia ferrea & Pau Ferro & NP \\
\hline $\mathrm{CA}, \mathrm{CV}, \mathrm{BD}, \mathrm{PV}, \mathrm{PI}$ & Senna multijuga & Pau cigarra & $\mathbf{P}$ \\
\hline $\mathrm{BD}, \mathrm{CA}, \mathrm{CV}, \mathrm{PV}$ & $\underline{\text { Schinus terebenthifolius }}$ & Aroeira- Mansa & $\mathbf{P}$ \\
\hline $\mathrm{BD}, \mathrm{CV}, \mathrm{CA}, \mathrm{PV}$ & $\underline{\text { Tapirira guianensis }}$ & $\begin{array}{l}\text { Peito de Pombo, } \\
\text { Copiúva }\end{array}$ & $\mathbf{P}$ \\
\hline $\mathrm{BD}, \mathrm{PV}$ & Lithraea molleoides & Aroeira- brava & $\mathbf{P}$ \\
\hline $\mathrm{BD}, \mathrm{CV}, \mathrm{PV}, \mathrm{PI}$ & Myracrodruon urundeuva & Aroeira- preta & $\mathbf{P}$ \\
\hline $\mathrm{BD}, \mathrm{CA}, \mathrm{PV}, \mathrm{PI}$ & Annona cacans & Araticum & $\mathbf{P}$ \\
\hline $\mathrm{BD}, \mathrm{CV}, \mathrm{PV}, \mathrm{PI}$ & Gochnatia polymorpha & Cambará & $\mathbf{P}$ \\
\hline $\mathrm{BD}, \mathrm{CV}, \mathrm{PV}, \mathrm{PI}$ & $\underline{\text { Chorisia speciosa }}$ & Paineira & $\mathbf{P}$ \\
\hline $\mathrm{BD}, \mathrm{PV}$ & Cecropia glazioui & $\begin{array}{l}\text { Embaúba- Verme- } \\
\text { Iha }\end{array}$ & $\mathbf{P}$ \\
\hline $\mathrm{BD}, \mathrm{CV}, \mathrm{PV}, \mathrm{PI}$ & $\underline{\text { Terminalia argentea }}$ & Capitão & $\mathbf{P}$ \\
\hline $\mathrm{BD}, \mathrm{CV}, \mathrm{PV}, \mathrm{PI}$ & $\underline{\text { Terminalia brasiliensis }}$ & Amarelinho & $\mathbf{P}$ \\
\hline $\mathrm{BD}, \mathrm{CV}, \mathrm{PV}, \mathrm{PI}$ & $\underline{\text { Terminalia trifolia }}$ & Capitãzinho & $\mathbf{P}$ \\
\hline $\mathrm{BD}, \mathrm{CA}, \mathrm{CV}, \mathrm{PV}, \mathrm{PI}$ & Erythrina sp & Eritrina & $\mathbf{P}$ \\
\hline $\mathrm{BD}, \mathrm{CV}, \mathrm{PV}$ & Alchorneae glanulosa & Boleira, Tapiá & $\mathbf{P}$ \\
\hline $\mathrm{BD}, \mathrm{CA}, \mathrm{CV}, \mathrm{PV}$ & Eugenia brasiliensis & Grumixama & $\mathbf{P}$ \\
\hline $\mathrm{BD}, \mathrm{CA}, \mathrm{CV}, \mathrm{PV}$ & $\underline{\text { Trema micrantha }}$ & Pau - Polvora & $\mathbf{P}$ \\
\hline $\mathrm{BD}, \mathrm{CV}, \mathrm{PV}, \mathrm{PI}$ & $\underline{\text { Croton urucurana }}$ & Capixingui & $\mathbf{P}$ \\
\hline $\mathrm{BD}, \mathrm{CV}, \mathrm{PV}, \mathrm{PI}$ & Peltophorum dubium & Canafistula & $\mathbf{P}$ \\
\hline $\mathrm{BD}, \mathrm{CV}, \mathrm{PV}, \mathrm{PI}$ & Senna multijuga & Pau - Cigarra & $\mathbf{P}$ \\
\hline $\mathrm{BD}, \mathrm{CA}, \mathrm{CV}, \mathrm{PV}$ & Bauhinia forficata & Pata de Vaca & $\mathbf{P}$ \\
\hline $\mathrm{BD}, \mathrm{CV}$ & Parapiptadenia rigida & $\begin{array}{l}\text { Angico branco do } \\
\text { mato }\end{array}$ & $\mathbf{P}$ \\
\hline BD & $\underline{\text { Albizia hassleri }}$ & Farinha-Seca & $\mathbf{P}$ \\
\hline $\mathrm{BD}, \mathrm{CA}, \mathrm{CV}$ & Inga sp. & Ingá & $\mathbf{P}$ \\
\hline BD & Rapanea ssp. & Capororoca & $\mathbf{P}$ \\
\hline $\mathrm{BD}, \mathrm{CA}, \mathrm{CV}, \mathrm{PV}$ & Psidium guajava & Goiaba & $\mathbf{P}$ \\
\hline
\end{tabular}




\begin{tabular}{|c|c|c|c|}
\hline $\mathrm{BD}, \mathrm{CV}, \mathrm{PV}$ & Machaerium villosum & $\begin{array}{l}\text { Jacarandá Pau- } \\
\text { lista }\end{array}$ & $\mathbf{P}$ \\
\hline $\mathrm{BD}, \mathrm{CA}, \mathrm{CV}, \mathrm{PV}, \mathrm{PI}$ & Eugenia dysenterica & Cagaita & NP \\
\hline $\mathrm{BD}, \mathrm{CA}, \mathrm{CV}, \mathrm{PV}, \mathrm{PI}$ & Matayba eleagnoides & Camboatã & $\mathbf{P}$ \\
\hline $\mathrm{BD}, \mathrm{CA}, \mathrm{CV}, \mathrm{PV}, \mathrm{PI}$ & $\underline{\text { Qualea multiflora }}$ & Pau Tucano & $\mathbf{P}$ \\
\hline $\mathrm{BD}, \mathrm{PV}$ & Qualea jundiahy & Pau Terra & $\mathbf{P}$ \\
\hline $\mathrm{BD}$ & Solanum Iycocarpum & Lobeiro & $\mathbf{P}$ \\
\hline $\mathrm{BD}, \mathrm{CA}, \mathrm{CV}, \mathrm{PV}$ & $\underline{\text { Solanum paniculatum }}$ & Jurubeba & $\mathbf{P}$ \\
\hline $\mathrm{BD}, \mathrm{CA}, \mathrm{PV}$ & Trema micrantha & Crindiúva & $\mathbf{P}$ \\
\hline BD,CV.PV,PI & Vitex montevidensis & Tarumã & $\mathbf{P}$ \\
\hline $\mathrm{BD}, \mathrm{PV}, \mathrm{PI}$ & Ficus glabrata & Figueira & $\mathbf{P}$ \\
\hline $\mathrm{BD}, \mathrm{CA}, \mathrm{CV}, \mathrm{PV}$ & Rapanea ferruginea & Capororoca & $\mathbf{P}$ \\
\hline $\mathrm{BD}, \mathrm{CA}, \mathrm{CV}, \mathrm{PV}$ & Eugenia leitonni & Goiabão & NP \\
\hline $\mathrm{BD}, \mathrm{CV}, \mathrm{PI}, \mathrm{PV}$ & Schizolobium parahyba & Guapuruvu & NP \\
\hline $\mathrm{BD}, \mathrm{CV}, \mathrm{PI}, \mathrm{PV}$ & Cedrela fissilis & Cedro & NP \\
\hline $\mathrm{BD}, \mathrm{CA}, \mathrm{CV}, \mathrm{PI}, \mathrm{PV}$ & $\underline{\text { Tabebuia ssp }}$ & Ipê roxo & NP \\
\hline BD, CA. CV, PI, PV & Tabebuia ssp & Ipê amarelo & NP \\
\hline $\mathrm{BD}, \mathrm{CA}, \mathrm{CV}, \mathrm{PI}, \mathrm{PV}$ & $\begin{array}{l}\text { Aspidosperma Cylindrocar- } \\
\text { pon }\end{array}$ & Peroba - Poca & NP \\
\hline $\mathrm{BD}, \mathrm{PV}$ & Aspidosperma polyneuron & Peroba - Rosa & NP \\
\hline $\mathrm{BD}, \mathrm{CV}, \mathrm{PV}, \mathrm{PI}$ & Aspidosperma ramiflorum & Guatambú & NP \\
\hline $\mathrm{BD}, \mathrm{CA}, \mathrm{CV}, \mathrm{PV}$ & Albizia polycephala & Angico Branco & NP \\
\hline $\mathrm{BD}, \mathrm{CV}, \mathrm{PV}$ & $\underline{\text { Pterogyne nitens }}$ & $\begin{array}{l}\text { Amendoim- } \\
\text { - Bravo }\end{array}$ & $\mathbf{p}$ \\
\hline $\mathrm{BD}, \mathrm{CV}, \mathrm{PV}, \mathrm{PI}$ & $\underline{\text { Andira inermis }}$ & Angelim & NP \\
\hline $\mathrm{BD}, \mathrm{CV}, \mathrm{PV}$ & Andira fraxinifolia & Angelim-doce & NP \\
\hline $\mathrm{BD}, \mathrm{CV}, \mathrm{PV}$ & Andira anthelmia & $\begin{array}{l}\text { Angelim - amar- } \\
\text { goso }\end{array}$ & NP \\
\hline $\mathrm{BD}, \mathrm{CV}, \mathrm{PV}, \mathrm{PI}$ & Centrolobium tomentosum & Araribá & NP \\
\hline $\mathrm{BD}, \mathrm{CV}, \mathrm{PV}$ & Machaerium nyctitans & $\begin{array}{l}\text { Jacarandá bico- } \\
\text { de pato }\end{array}$ & NP \\
\hline $\mathrm{BD}, \mathrm{CV}, \mathrm{PV}, \mathrm{PI}$ & Machaerium scleroxylon & Caviúna & NP \\
\hline $\mathrm{BD}, \mathrm{CV}, \mathrm{PV}$ & Ficus guaranitica & Figueira branca & NP \\
\hline $\mathrm{BD}, \mathrm{PV}$ & Gallesia integrifolia & Pau d'alho & NP \\
\hline $\mathrm{BD}, \mathrm{PV}$ & Prunus myrtifolia & $\begin{array}{l}\text { Pessegueiro } \\
\text { Bravo }\end{array}$ & NP \\
\hline
\end{tabular}




\begin{tabular}{|l|l|l|c|}
\hline BD, CV, CA, PV & lnga edulis & Ingá de metro & NP \\
\hline BD, CV, PV & Lafoensia glyptocarpa & Mirindiba & NP \\
\hline BD, CV, CA, PI, PV & Tabebuia avellanedae & Ipê rosa & NP \\
\hline BD, CV, PV & Caesalpinia peltophoroides & Sibipiruna & NP \\
\hline BD, PV & Cariniana estrellensis & Jequitibá branco & NP \\
\hline BD, CV, CA,PI, PV & Citrarexylum myrianthum & Pau viola & $\mathbf{p}$ \\
\hline BD, PV & Cariniana legalis & Jequitibá rosa & NP \\
\hline BD, CV, PV & Mayna brasiliensis & Canudo de pito & $\mathbf{P}$ \\
\hline BD, CV, PV & Calophyllum brasiliensis & Guanandi & NP \\
\hline BD, CV, PV & Triplaris brasiliensis & Pau formiga & P \\
\hline BD, CV, CA, PI, PV & Lafoensia pacari & Dedaleiro & NP \\
\hline BD, CV, CA & Guazuma ulmifolia & Mutambo & P \\
\hline BD, CV, CA, PI, PV & Tabebuia roseo-alba & Ipê branco & NP \\
\hline
\end{tabular}

Legenda: CA calçadas, CV corredores verdes, BD bolsões de diversidade, $\mathrm{PV}$ permanência verão, $\mathrm{PI}$ permanência inverno, P pioneira, NP não pioneira (secundária ou clímax) 